\title{
ANALISIS KESALAHAN BERBAHASA DALAM KEGIATAN SEMINAR PROPOSAL PENELITIAN MAHASISWA PROGRAM STUDI PENDIDIKAN BAHASA DAN SASTRA INDONESIA STKIP NIAS SELATAN TAHUN AKADEMIK 2018/2019
}

\section{ANALYSIS OF LANGUAGE MISTAKES IN STUDENT RESEARCH PROPOSAL SEMINAR ACTIVITIES AT INDONESIAN LANGUAGE AND LITERATURE EDUCATION STUDY PROGRAM OF STKIP NIAS SELATAN IN ACADEMIC YEAR 2018/2019}

\author{
MERRI CHRISTINA ZALUKHU ${ }^{1)}$; UJIANHATI ZEGA ${ }^{2)}$ \\ Dosen Prodi Pendidikan Bahasa dan Sastra Indonesia STKIP Nias Selatan ${ }^{1)}$ \\ Dosen Prodi Pendidikan Biologi STKIP Nias Selatan ${ }^{2)}$ \\ Jl. Pramuka, Nari-Nari, Kel. Pasar Telukdalam, Kec. Telukdalam, Nias Selatan, Sumatera Utara \\ *Email : merrichristinaz@gmail.com \\ ujianzega@gmail.com
}

Abstrak. Kesalahan-kesalahan berbahasa masih ditemukan khususnya pada forum seminar proposal penelitian mahasiswa Program Studi Pendidikan Bahasa dan Sastra Indonesia STKIP Nias Selatan. Dalam kegiatan seminar proposal penelitian mahasiswa sering menggunakan tuturan yang berulangulang bahkan kadang menggunakan tuturan yang sehrusnya tidak perlu diucapkan. Penelitian ini bertujuan untuk mendeskripsikan kesalahan berbahasa lisan dalam bentuk kesalahan penghilangan (omission), kesalahan penambahan (addition), kesalahan formasi (misformation), dan kesalahan susun (misordering) dalam kegiatan seminar proposal penelitian mahasiswa Program Studi Pendidikan Bahasa dan Sastra Indonesia tahun akademik 2018/2019. Metode penelitian yang digunakan adalah deskriptif kualitatif. Sumber data dalam penelitian ini adalah mahasiswa yang diuji pada seminar proposal penelitian pada program studi Pendidikan Bahasa dan Sastra Indonesia STKIP Nias Selatan Tahun Akademik 2018/2019. Teknik pengumpulan data dalam penelitian ini menggunakan metode dokumentasi yang diawali dengan metode rekam dan dilanjutkan dengan transkripsi data. Teknik analisis data yang digunakan adalah teknik Miles dan Huberman: reduksi data, penyajian data, dan pengambilan kesimpulan. Target akhir tingkat kesiapan teknologi adalah 2 . Berdasarkan hasil penelitian, ditemukan bahwa kesalahan yang paling banyak dilakukan oleh penutur adalah kesalahan penambahan kata atau frase (52). Sedangkan kesalahan yang paling sedikit terjadi adalah kesalahan penghilangan kata atau frase (24). Selain itu, ditemukan bahwa hampir pada setiap tuturan yang diucapkan oleh mahasiswa peserta seminar terdapat minimal satu jenis kesalahan. Tuturan yang di dalamnya terdapat keempat jenis kesalahan berjumlah 10 kalimat. Hal ini mengindikasikan bahwa mahasiswa yang diuji pada seminar proposal penelitian masih belum mampu berbahasa Indonesia yang baik dan benar. Mahasiswa masih sering menambahkan kata/frase/klausa yang seyogianya tidak perlu ditambahkan sehingga makna kalimat bagi penutur dan atau pendengar tidak jelas (samar). Hal ini berdampak pada makna wacana secara keseluruhan. Peneliti menyarankan: (1) tenaga pendidik secara khusus pada program studi Bahasa dan Sastra Indonesia harus memberikan perhatian khusus pada penanaman cara berbahasa Indonesia yang baik dan benar pada setiap proses pembelajaran; (2) mahasiswa khususnya pada program studi Bahasa dan Sastra Indonesia harus selalu belajar dan berlatih menggunakan bahasa Indonesia yang baik dan benar terutama pada situasi formal.

Kata Kunci: kesalahan berbahasa, seminar, proposal penelitian

\begin{abstract}
Language errors are still found especially at the seminar forum for research proposals for students of the Indonesian Language and Literature Education Study Program, STKIP, South Nias. In seminar activities research proposals students often use repetitive utterances and sometimes even use utterances that should not need to be said. This study aims to describe oral language errors in the form of omissions, errors, misformations, and misordering in the research proposal seminar activities for students of the Indonesian Language and Literature Education Study Program in 2018 academic year / 2019. The research method used is descriptive qualitative. Data sources in this study were students who were tested at a research proposal seminar on the Indonesian Language and Literature Education study program STKIP South Nias Academic Year 2018/2019. Data collection techniques in this study used the documentation method that began with the record method and continued with data transcription. The data analysis technique used is the Miles and Huberman technique: data reduction, data presentation, and drawing conclusions. The final target of the level of technological readiness is
\end{abstract}


2. Based on the results of the study, it was found that the most mistakes made by the speakers were mistakes in adding words or phrases (52). While the fewest mistakes occur are mistakes in missing words or phrases (24). In addition, it was found that almost every speech uttered by seminar participants was at least one type of error. Speech in which there are four types of errors totaling 10 sentences. This indicates that the students who were tested at the research proposal seminar were still unable to speak Indonesian properly. Students still often add words / phrases / clauses that should not need to be added so that the meaning of the sentence for the speaker and / or listener is not clear (vague). This has an impact on the meaning of discourse as a whole. The researcher recommends: (1) teaching staff specifically in the Indonesian Language and Literature study program should pay special attention to the cultivation of Indonesian language that is good and right in each learning process; (2) students, especially in the Indonesian Language and Literature study program must always learn and practice using good and correct Indonesian, especially in formal situations.

Keywords: language errors, seminars, research proposals

\section{Pendahuluan}

Bahasa merupakan alat yang digunakan manusia untuk berkomunikasi. Bahasa digunakan oleh manusia untuk berinteraksi sosial dan mengidentifikasi diri. Kridaklasana dalam Chaer (2010:32) mengidentifikasikan, "Bahasa adalah sistem lambang yang arbitrer yang digunakan oleh masyarakat untuk bekerja sama, berinteraksi, dan mengidentifikasi diri". Pada dasarnya, bahasa digunakan oleh manusia untuk menuangkan ide, gagasan dan perasaan kepada orang lain. Sebaliknya, bahasa dapat digunakan untuk menerima ide, gagasan dan perasaan dari orang lain.

Komunikasi dapat dilakukan oleh manusia melalui bahasa lisan dan bahasa tulis yang fungsinya adalah untuk berkomunikasi. Bahasa yang dilakukan secara lisan berarti seseorang itu dapat langsung menyampaikan pesan kepada lawan bicaranya sehingga pesan langsung sampai kepada yang dituju, sedangkan secara tulis lebih cenderung terstruktur dan teratur karena pesan yang akan disampaikan kepada penerima pesan dan waktunya pun cenderung lebih lama, namun isi pesan mampu dipertanggungjawabkan kepda pembaca secara umum.

Sebagai kaum terpelajar, para mahasiswa dituntut untuk mampu menuangkan ide, serta mampu menyesuaikan bahasa yang digunakan sesuai dengan konteks, dan bisa menggunakan bahasa Indonesia dengan baik dan benar dalam mengkomunikasikan ilmunya. Berbahasa yang baik dan benar itu penting untuk digunakan oleh mahasiswa, karena bahasa sebagai panduan untuk penyususnan dan penggunaan tata bahasa yang baik dan benar dalam komunikasi ilmiah (skripsi), selain itu mahasiswa mampu mengkomunikasikan tata bahasa dengan baik dan benar. Menurut Sugono (2009:21), "Bahasa bukan sekedar alat komunikasi, bahasa itu alat pikir dan alat ekspresi maka bahasa itu bersistem. Oleh karena itu, berbahasa bukan sekedar berkomunikasi (asal mengerti/pokoknya mengerti), berbahasa perlu menaati kaidah atau aturan berbahasa yang berlaku".

Mahasiswa merupakan salah satu pengguna bahasa sekaligus sebagai tumpuan harapan dalam menerapkan bahasa yang baik dan benar. Mahasiswa seharusnya sedapat mungkin menghindari kesalahan berbahasa karena telah mendapat bekal pengetahuan tentang bahasa yang baik dan benar dan merupakan calon pengajar bahasa Indonesia. Namun pada kenyataannya, masih ditemukan mahasiswa yang melakukan kesalahan berbahasa dalam menyampaikan tuturannya terutama pada forum ilmiah seperti pada kegiatan seminar proposal. Oleh sebab itu, pemahaman mahasiswa terhadap bentuk-bentuk kesalahan berbahasa harus ditingkatkan agar kesalahankesalahan berbahasa Indonesia dapat dihindari dengan baik. Kegiatan seminar bertujuan untuk melatih mahasiswa menyampaikan argumen, ide, atau solusi dalam menyelesaikan masalah akademik melalui penelitian. Mahasiswa yang menjadi penyaji pada seminar proposal penelitian dituntut mampu memaparkan dan mempertanggungjawabkan proposal penelitian dengan menggunakan bahasa secara lisan yang baik dan benar.

Dalam kegiatan seminar maupun meja hijau, mahasiswa membutuhkan komunikasi yang baik dalam menyajikan rancangan penelitian maupun skripsinya. Mereka wajib menggunakan bahasa yang baik dan benar karena kegiatan tersebut merupakan forum ilmiah. Sebagai calon sarjana, mahasiswa dipersiapkan untuk berbahasa dengan baik dan benar agar mahasiswa tidak hanya menjadi konsumen ilmu melainkan juga sebagai penghasil atau pengguna bahasa sesuai bidang ilmu masing-masing. Kesalahan-kesalahan berbahasa masih ditemukan khususnya pada forum seminar proposal penelitian mahasiswa Program Studi Pendidikan Bahasa dan Sastra Indonesia STKIP Nias 
Selatan. Dalam kegiatan seminar proposal penelitian mahasiswa sering menggunakan tuturan yang berulang-ulang bahkan kadang menggunakan tuturan yang sehrusnya tidak perlu diucapkan.

Contoh kesalahan berbahasa yang ditemukan pada peserta seminar pada tanggal 3 Februari 2017, "Demikian hasil proposal penelitian saya, saya kembalikan kepada moderator". Pada tuturan di atas ditemukan kesalahan penambahan dan penghilangan. Kesalahan penambahan tampak pada kata yang seharusnya tidak perlu digunakan, seperti pada kata "Saya" dan "hasil". Kesalahan penghilangan ditandai oleh ketiadaan kata "pemaparan". Seharusnya konstruksi kalimat di atas adalah "Demikian pemaparan proposal penelitian ini, saya kembalikan kepada moderator".

Analisis kesalahan berbahasa adalah metode yang tepat untuk menguraikan bentuk-bentuk kesalahan berbahasa. Dalam kesalahan berbahasa, terdapat berbagai pendekatan, (1) pendekatan taksonomi kategori linguistik, (2) pendekatan taksonomi siasat permukaan, (3) pendekatan taksonomi komporatif dan (4) pendekatan efek komunikatif. Salah satu pendekatan yang peneliti gunakan dalam penelitian ini adalah taksosnomi siasat permukaan. Taksonomi siasat permukaan adalah suatu bentuk analisis kesalahan berbahasa yang menekankan pada cara-cara struktur permukaan berubah. Taksonomi siasat permukaan memiliki 4 (empat) aspek analisis (Tarigan, 2011:148), yaitu: 1) omission (kesalahan penghilangan), 2) addition (kesalahan penambahan), 3) misformation (kesalahan formasi), dan 4) misordering (kesalahan susun). Empat aspek analisis tersebut dinilai paling tepat digunakan dalam penelitian ini karena bertujuan menguraikan bentuk-bentuk kesalahan berbahasa Indonesia tuturan mahasiswa dalam kegiatan seminar proposal penelitian mahasiswa Program Studi Pendidikan Bahasa dan Sastra Indonesia STKIP Nias Selatan, karena kesalahan berbahasa itu bukanlah semata-mata harus dihindari melainkan harus dipelajari melalui proses pemerolehan dan pengajaran.

Analisis taksonomi siasat permukaan ini mampu menjabarkan bentuk kesalahan berbahasa yang sering dilakukan para mahasiswa. Kesalahan tersebut berupa penyusunan kalimat dan menghilangkan/menambahkan unsur-unsur yang seharusnya tidak diperlukan sehingga seringkali membuat kesalahan berbahasa mahasiswa dalam penggunaan bahasa Indonesia. dari analisis ini diharapkan mampu memberi pemahaman terhadap penggunaan bahasa Indonesia yang baik dan benar, baik secara lisan maupun tulisan.

Merujuk pada latar belakang di atas maka penelitian ini akan berusaha mengungkap kesalahan berbahasa lisan dalam kegiatan seminar proposal penelitian mahasiswa program studi Pendidikan Bahasa dan Sastra Indonesia tahun akademik 2018/2019. Batasan masalah dalam penelitian ini adalah kesalahan berbahasa bentuk penghilangan (omission), kesalahan penambahan (addition), kesalahan formasi (misformation), dan kesalahan susun (misordering) dalam kegiatan seminar proposal penelitian mahasiswa Program Studi Pendidikan Bahasa dan Sastra Indonesia STKIP Nias Selatan tahun akademik 2018/2019. Rumusan masalah dalam penelitian ini adalah apa saja bentuk-bentuk kesalahan berbahasa yang dilakukan oleh mahasiswa program studi Pendidikan Bahasa dan Sastra Indonesia STKIP Nias Selatan Tahun Akademik 2018/2019.

Penelitian ini bertujuan untuk mendeskripsikan kesalahan berbahasa baik dalam bentuk kesalahan penghilangan (omission), kesalahan penambahan (addition), kesalahan formasi (misformation), dan kesalahan susun (misordering) dalam kegiatan seminar proposal penelitian mahasiswa Program Studi Pendidikan Bahasa dan Sastra Indonesia STKIP Nias Selatan tahun akademik 2018/2019. Target luaran yang ingin dicapai adalah artikel ilmiah yang telah dipublikasikan pada jurnal nasional.

\section{Metodologi Penelitian}

Untuk menjawab pertanyaan pada fokus masalah penelitian sebagaimana yang telah dikemukakan pada bagian terdahulu, maka pendekatan yang digunakan dalam penelitian ini yaitu: pendekatan kualitatif dengan jenis metode penelitian deskriptif yang memerlukan pemecahan masalah berdasarkan data-data yang ada, menganalisis dan menginterpretasikan. Penelitian ini menganalisis data yang berupa tuturan bahasa lisan dalam seminar proposal penelitian mahasiswa Program Studi Pendidikan Bahasa dan Sastra Indonesia STKIP Nias Selatan tahun 
$\mathcal{H a l}: 24-30$

akademik 2018/2019. Tuturan tersebut dideskripsikan sesuai dengan tataran kesalahan taksonomi siasat pemukaan.

Penelitian ini dilaksanakan di kampus STKIP Nias Selatan,khususnya di Program Studi Pendidikan Bahasa dan Sastra Indonesia STKIP Nias Selatan tahun akademik 2018/2019 pada saat kegiatan seminar proposal penelitian.

Waktu penelitian direncanakan pada semester genap tahun akademik 2018/2019. Jenis data yang digunakan peneliti dalam penelitian ini yaitu data primer. Sumber data dalam penelitian ini adalah tuturan mahasiswa penyaji dalam kegiatan seminar proposal penelitian Program Studi Pendidikan Bahasa dan Sastra Indonesia STKIP Nias SelatanTahun Akademik 2018/2019.

Sumber data primer dalam penelitian ini adalah mahasiswa Program Studi Pendidikan Bahasa dan Sastra Indonesia STKIP Nias Selatan yang mengadakan seminar proposal pada semester genap Tahun Akademik 2018/2019.

Metode pengumpulan data dalam penelitian ini menggunakan metode rekam-catat yang diawali dengan metode rekam dan dilanjutkan dengan transkripsi data. Adapun langkah-langkah yang peneliti lakukan dalam pengumpulan data yaitu sebagai berikut:

a. Peneliti merekam (memvideokan) data pelaksanaan kegiatan seminar proposal penelitian mahasiswa Program Studi Pendidikan Bahasa dan Sastra Indonesia Tahun Akademik 2018/2019.

b. Peneliti mentranskripsi data hasil rekaman (menulis kembali).

c. Peneliti mengklasifikasikan data (menandai data).

d. Peneliti menganalisis data.

e. Peneliti menyimpulkan atau melaporkan hasil penelitian.

Pada analisis data kualitatif dilakukan bersama dengan proses pengumpulan data. Teknik analisis yang dilakukan dengan menggunakan teknik analisis data yang dikemukakan oleh Miles dan Huberman dalam Emzir (2012:129-135) mencakup tiga kegiatan yang bersamaan: (1) Reduksi data, (2) Penyajian data, dan (3) Penarikan kesimpulan (verifikasi).

Pengecekan keabsahan data dalam penelitian ini dilakukan dengan teknik triangulasi. Ghony dan Almanshur(2016:322) "Teknik triangulasi adalah teknik pemeriksaan keabsahan data yang memanfaatkan sesuatu yang lainnya di luar data itu untuk keperluan pengecekan atau sebagai pembanding terhadap data itu". Burns dalam Rusyani (2008:26) mengatakan bahwa untuk itu dalam penelitian triangulasi dilakukan dengan cara: triangulasi data, situasional, dan metode pengumpulan data. Jenis triangulasi yang digunakan adalah triangulasi waktu.

\section{Hasil dan Pembahasan}

Metode penelitian yang digunakan adalah metode deskriptif kualitatif. Sumber data dalam penelitian ini adalah mahasiswa peserta ujian seminar proposal pada tahun akademik 2018/2019 semester genap. Data dalam penelitian ini berupa kalimat lengkap (mayor), bukan kalimat tidak lengkap (minor) yang biasanya berupa jawaban singkat. Data penelitian ini berjumlah 70 tuturan (kalimat). Teknik pengumpulan data yang digunakan dalam penelitian ini adalah teknik rekam-catat sedangkan teknik analisis datanya adalah teknik Miles dan Huberman yang terdiri dari reduksi data, penyajian data, dan verifikasi (penarikan kesimpulan). Pertama, peneliti merekam setiap tuturan (jawaban) mahasiswa peserta ujian seminar ketika menanggapi pertanyaan audience dan dosendosen penguji dengan memvideokannya menggunakan alat perekam berupa HP android. Kedua, peneliti mentranskripsikan tuturan (jawaban) mahasiswa peserta ujian seminar proposal ke dalam tulisan. Ketiga, peneliti merancang panduan analisis kesalahan berbahasa berupa tabel analisis yang berfokus pada jenis kesalahan berbahasanya. Untuk menjaring kesalahan berbahasa yang dilakukan oleh mahasiswa, peneliti menggunakan teknik Siasat Permukaan, yaitu teknik analisis kesalahan yang memandang kesalahan hanya terdiri dari empat jenis: penghilangan, penambahan, salah bentuk, dan salah susun. Data-data yang telah ditranskripsikan direduksi dan disajikan dengan pengelompokan. Peneliti berpandangan bahwa kondisi yang tepat untuk mengetahui kesalahan berbahasanya adalah ketika merespons pertanyaan orang lain. Bahasa yang muncul adalah haruslah bahasa alami penutur yang tidak terkesan dihafal atau dibaca. Oleh karena itu, peneliti benar-benar menyeleksi tuturan mahasiswa untuk ditranskripsikan.

Setelah dianalisis, kesalahan-kesalahan berbahasa yang dilakukan oleh penutur (mahasiswa) pada setiap kalimat yang diucapkan tidaklah mengacu pada satu jenis kesalahan. Bisa saja terdapat dua jenis kesalahan pada satu kalimat bahkan empat. Akibat kesalahan-kesalahan tersebut makna kalimat menjadi tidak jelas bahkan sulit dipahami.

\section{a. Penghilangan (Ommision)}


Kesalahan penghilangan (omission) adalah kesalahan-kesalahan yang bersifat "penghilangan" yang ditandai oleh ketidakhadiran suatu butir yang seharusnya ada di dalam ucapan yang baik dan benar. berikut.

Beberapa kesalahan penghilangan yang ditemukan melalui penelitian ini adalah sebagai

1) Misalnya, Pak, orangtua sering menggunakan ketika mereka tarian di depan teras misalnya.

2) Data dalam penelitian itu majas perbandingan.

Kata yang hilang pada kalimat (a) adalah klitik -nya. Seharusnya, kalimat yang benar adalah Pak, misalnya, orangtua sering menggunakannya ketika mereka menari di depan teras. Sedangkan, kata yang hilang pada kalimat (b) adalah kata adalah. Seharusnya, kalimat yang benar adalah Data dalam penelitian ini adalah majas perbandingan.

\section{b. Penambahan (addition)}

Kesalahan penambahan (addition), adalah kebalikan dari penghilangan. Kesalahan penambahan ditandai oleh hadirnya suatu butir atau unsur yang seharusnya tidak muncul dalam ujaran yang baik dan benar.

Beberapa kesalahan penambahan yang ditemukan melalui penelitian ini adalah sebagai berikut.

1) Mengingat karena penelitian ini berupa nonfiksi atau berupa dokumentasi maka tempat

penelitiannya bisa dilakukan dimana saja.

2) la melewati sembilan sungai dan dia melewati lembah yang luas.

Kata yang tidak seharusnya ditambah pada kalimat (a) adalah kata karena sebab kata tersebut sejajar maknanya dengan kata mengingat sehingga sebaiknya salah satu saja yang dipakai. Selain itu, kata berupa tidak perlu dipakai dua kali dalam kalimat. Perbaikan kalimat tersebut adalah Mengingat penelitian ini berupa dokumentasi maka tempat penelitiannya bisa dilakukan dimana saja. Sedangkan kata yang tidak seharusnya ditambah pada kalimat kedua adalah kata dia dan melewati sebab telah digunakan pada klausa pertama. Perbaikan kalimat tersebut adalah la melewati sembilan sungai dan lembah yang luas.

\section{c. Salah Bentuk (misformation)}

Kesalahan formasi (misformation), ditandai oleh pemakaian bentuk morfem atau struktur kata yang salah yang dimunculkan dalam praktik berbahasanya walaupun hal itu salah.

Beberapa kesalahan bentuk yang ditemukan melalui penelitian ini adalah sebagai berikut.

1) Kemudian saya tanya apakah informan ini benar-benar penduduk desa Fondrako Raya atau bukan.

2) Kemudian apakah dia juga tahu tentang kosakata-kosakata yang digunakan oleh orangtua pada zaman dahulu.

Kesalahan bentuk pada kalimat (a) adalah kata tanya dan seharusnya diubah menjadi kata bertanya sehingga perbaikan kalimat tersebut Kemudian saya bertanya apakah informan ini benarbenar penduduk desa Fondrako Raya atau bukan. Sedangkan kesalahan bentuk pada kalimat (b) adalah kata tahu dan seharusnya diubah menjadi mengetahui sehingga perbaikan kalimat tersebut Kemudian apakah dia juga mengetahui tentang kosakata-kosakata yang digunakan oleh orangtua pada zaman dahulu.

\section{d. Salah Susun (misordering)}

Kesalahan susun (misodering) ditandai oleh penempatan morfem atau kelompok morfem yang tidak benar dalam suatu ucapan atau ujaran.

Beberapa kesalahan susun yang ditemukan melalui penelitian ini adalah sebagai berikut.

1) Tidak langsung saya tanyakan kepada informan tersebut.

2) Karena sudah saya gabungkan semua.

Kesalahan susun pada kalimat (a) adalah subjek saya diletakkan setelah predikat tidak langsung. Seharusnya, subjek harus mendahului predikat sehingga perbaikan kalimat tersebut adalah Saya tidak langsung bertanya kepada informan tersebut. Sedangkan kesalahan susun pada kalimat (b) adalah subjek semua diletakkan setelah predikat sudah (saya) gabungkan sehingga perbaikan kalimat itu seharusnya Karena semua sudah saya gabungkan. 
Berdasarkan hasil analisis data, kesalahan yang paling banyak dilakukan oleh penutur adalah kesalahan penambahan kata atau frase (52). Sedangkan kesalahan yang paling sedikit terjadi adalah kesalahan penghilangan kata atau frase (24). Selain itu, ditemukan bahwa hampir pada setiap tuturan yang diucapkan oleh mahasiswa peserta seminar terdapat minimal satu jenis kesalahan. Tuturan yang di dalamnya terdapat keempat jenis kesalahan berjumlah 10 kalimat. Hal ini mengindikasikan bahwa mahasiswa yang diuji pada seminar proposal penelitian masih belum mampu berbahasa Indonesia yang baik dan benar. Mahasiswa masih sering menambahkan kata/frase/klausa yang seyogianya tidak perlu ditambahkan sehingga makna kalimat bagi penutur dan atau pendengar tidak jelas (samar). Hal ini berdampak pada makna wacana secara keseluruhan.

\section{Kesimpulan dan Saran}

Berdasarkan hasil penelitian, dapat disimpulkan bahwa mahasiswa program studi Bahasa dan Sastra Indonesia masih sering melakukan kesalahan dalam menyampaikan pendapat, ide, gagasan, atau tanggapannya pada saat seminar proposal penelitian. Kesalahan Penambahan merupakan kesalahan yang paling sering dilakukan selain kesalahan penghilangan, susun, dan bentuk. Selain itu, masih terdapat banyak tuturan yag mengandung semua jenis kesalahan berbahasa. Akibatnya pendengar bahkan si penutur sendiri tidak memahami dengan jelas apa yang hendak disampaikannya.

Untuk itu, disarankan beberapa hal sebagai berikut.

a. Tenaga pendidik/dosen secara khusus pada program studi Bahasa dan Sastra Indonesia harus memberikan perhatian khusus pada penanaman cara berbahasa Indonesia yang baik dan benar pada setiap proses pembelajaran;

b. Mahasiswa khususnya pada program studi Bahasa dan Sastra Indonesia tidak mengganggap remeh pembelajaran bahasa sebaliknya harus selalu belajar dan berlatih menggunakan bahasa Indonesia yang baik dan benar terutama pada situasi formal.

\section{Ucapan Terima Kasih}

Pada kesempatan ini penulis mengucapkan terima kasih yang sebesar-besarnya kepada Direktorat Riset dan Pengabdian Masyarakat, Direktorat Jenderal Penguatan Riset dan Pengembangan, Kementrian Riset, Teknologi, dan Pendidikan Tinggi yang telah menghibahkan dana penelitian kepada para penulis hingga proses penyelesaian.

\section{Daftar Pustaka}

(1) Chaer, Abdul. 2012. Linguistik Umum. Jakarta: Rineka Cipta.

(2) Emzir. 2012. Metodologi Penelitian Kualitatif Analisis Data. Jakarta: Rajawali.

(3) Ghony, M. Djunaidi dan Fauzan Almansyur. 2016. Metode Penelitian Kualitatif. Jogjakarta: ArRuzz Media.

(4) Kosasih. 2003. Ketatabahasaan dan Kesusastraan Bahasa Indonesia. Bandung: CV.YramaWidya.

(5) Ningsih, dkk. 2007. Bahasa Indonesia Untuk Mahasiswa. Yogyakarta: ANDI.

(6) Pranowo. 2014. Teori Belajar Bahasa (Untuk Guru Bahasa dan Mahasiswa Jurusan Bahasa). Yogyakarta: Pustaka Pelajar.

(7) Sugiyono. 2012. Metode Penelitian Pendidikan (Pendekatan Kuantitatif, Kualitatif, dan R\&D). Bandung: Angkasa.

(8) Sugono, Dendy. 2009. Mahir Bebahasa Indonesia dengan Benar. Jakarta: PT.Gramedia.

(9) Sulastri, Euis dkk. 2002. Bahasa dan Sastra Indonesia I untuk SMU kelas I. Bekasi: PT. Galaxy Puspa Mega (Anggota IKAPI).

(10) Tarigan, Henry Guntur. 2011. Pengajaran Analisis Kesalahan Berbahasa. Bandung: Angkasa.

(11) Indihadi, Dian 2012. Analisis Kesalahan Berbahasa. (Online), (http://www.scribd.com/doc/53411928/Analisis-Kesalahan-Berbahasa, diakses 20 Februari 2017).

(12) BPTP-PAATP, Tim Ahli. 1998. Pedoman Teknik Penyajian Informasi IImiah dalamseminar.(Online),(http:www.oocities.org/thetropics/lagoon/3449/PDF/seminar.pdf, diakses 28 Februari 2017).

(13) Notohadiprawiro, Tejoyuwono. 2006. Hakekat Seminar dan Tesis dalam Kurikulum Pendidikan Tinggi untuk Landasan Penyusun metode dan

TeknikPembimbingannya.(Online),(http://faperta.ugm.ac.id/download/publikasi dosen/tejoyuwon o/1981/1984\%20hake.pdf). 
Vol. 6, No. 2 (2019)

$\mathcal{H a l}: 24-30$

(14) Ayudia dkk. Analisis Kesalahan Penggunaan Bahasa Indonesia dalam Laporan Hasil Observasi pada Siswa SMP. BASASTRA:Jurnal Penelitian Bahasa, Sastra Indonesia, dan Pengajarannya, (online), https://media.peneliti.com/media/publications/53972-ID-analisis-kesalahan-penggunaanbahasa-ind.pdf) Vol. 4, No. 1 